\title{
On the Mechanical Properties of Hybrid Aluminium 7075 Matrix Composite Material Reinforced with SiC and TiC Produced by Powder Metallurgy Method
}

\author{
S. Pradeep Devaneyan, ${ }^{1}$ R. Ganesh, ${ }^{2}$ and T. Senthilvelan ${ }^{3}$ \\ ${ }^{1}$ Department of Mechanical Engineering, Christ College of Engineering and Technology, Pondicherry 605010, India \\ ${ }^{2}$ Department of Mechanical Engineering, S.S.N. College of Engineering, Chennai 603110, India \\ ${ }^{3}$ Department of Mechanical Engineering, Pondicherry Engineering College, Pondicherry 605014, India \\ Correspondence should be addressed to S. Pradeep Devaneyan; pr.signs@gmail.com
}

Received 23 July 2016; Revised 20 October 2016; Accepted 8 December 2016; Published 23 January 2017

Academic Editor: Federica Bondioli

Copyright ( 2017 S. Pradeep Devaneyan et al. This is an open access article distributed under the Creative Commons Attribution License, which permits unrestricted use, distribution, and reproduction in any medium, provided the original work is properly cited.

\begin{abstract}
Metal matrix composites are widely used in components of various components of industrial equipment because of their superior material properties like high stiffness to weight ratio and high impact strength and fracture toughness while compared to the conventional material. Due to the concepts of high strength to low weight ratio, Al 7075 was extensively applied in aircraft engine and wings. Even if $\mathrm{Al} 7075$ has higher hardness, higher strength, excellent wear resistance, and high-temperature corrosion protection, it is in need of further enhancement of properties for increasing its applicability. This paper presents the mechanical behavior of aluminium 7075 reinforced with Silicon Carbide $(\mathrm{SiC})$ and Titanium Carbide $(\mathrm{TiC})$ through powder metallurgy route. These specimens were produced by powder metallurgy method. The hybrid composite was made by Al 7075 alloy as the matrix with Silicon Carbide and Titanium Carbide as reinforcement. Silicon Carbide and Titanium Carbide are mixed in different weight ratio based on the design matrix formulated through a statistical tool, namely, Response Surface Methodology (RSM). Enhanced mechanical properties have been obtained with $90 \%$ of $\mathrm{Al} 7075,4 \%$ of $\mathrm{TiC}$, and $8 \%$ of SiC composition in the composite. Coefficient of friction appears to be more which has been determined by ring compression test.
\end{abstract}

\section{Introduction}

Powder metallurgy is one of the fast emerging routes in the industrial application because of its advantages such as high dimensional control and avoids secondary machining operation. Powder metallurgy is the method of producing a component to a net shape or near net shape [1]. Density of the components can be controlled easily through powder metallurgy method when compared to other manufacturing processes [2,3]. Aluminium 7075 is widely adopted in aircraft engines and wings, due to its advantageous properties such as high strength to low weight ratio, higher hardness, high strength, excellent wear resistance, and high-temperature corrosion protection [4]. Metal Matrix Composites (MMC) were highly known for their superior material properties like high stiffness to weight ratio and high impact strength and fracture toughness when compared to the conventional materials [5]. In the aerospace industry, metal matrix composite enables it to be applied extensively because of its superior properties [6]. Nanosized Silicon Carbide $(\mathrm{SiC})$ when embedded in the metals exhibits higher hardness, higher wear resistance, and corrosion resistance [7]. Hence, nano$\mathrm{SiC}$ particles can be embedded along with aluminium which is used to manufacture various machine elements like drive shafts, brake rotors, and brake drums in automobiles, for ventral fins and fuel access covers in aircraft to reduce wear. Similarly, nano-Titanium Carbide (TiC) possesses several advantages such as high specific strength, good corrosion resistance, and good wear property [1]. Along with these properties, Titanium Carbide has excellent strength to weight ratio which is particularly in need to the aerospace, chemical, and architectural industries. Literature reveals that MMC, in 
TABLE 1: Design matrix formulated by RSM.

\begin{tabular}{|c|c|c|c|c|c|}
\hline \multicolumn{3}{|c|}{ Actual value } & \multicolumn{3}{|c|}{ Coded value } \\
\hline$\%$ of $\mathrm{Al}$ & $\%$ of $\mathrm{SiC}$ & $\%$ of $\mathrm{TiC}$ & $\%$ of $\mathrm{Al}$ & $\%$ of $\mathrm{SiC}$ & $\%$ of $\mathrm{TiC}$ \\
\hline 100 & 0 & 8 & 1 & 1 & -1 \\
\hline 80 & 8 & 8 & -1 & -1 & -1 \\
\hline 90 & 4 & 0 & 0 & 0 & 1 \\
\hline 100 & 0 & 0 & 1 & 1 & 1 \\
\hline 80 & 0 & 8 & -1 & 1 & -1 \\
\hline 90 & 0 & 4 & 0 & 1 & 0 \\
\hline 90 & 4 & 4 & 0 & 0 & 0 \\
\hline 80 & 8 & 0 & -1 & -1 & 1 \\
\hline 90 & 4 & 4 & 0 & 0 & 0 \\
\hline 100 & 8 & 8 & 1 & -1 & -1 \\
\hline 90 & 4 & 4 & 0 & 0 & 0 \\
\hline 90 & 8 & 4 & 0 & -1 & 0 \\
\hline 90 & 4 & 8 & 0 & 0 & -1 \\
\hline 90 & 4 & 4 & 0 & 0 & 0 \\
\hline 100 & 8 & 0 & 1 & -1 & 1 \\
\hline
\end{tabular}

particular aluminium 7075 as matrix and $\mathrm{SiC} / \mathrm{TiC}$ as reinforcement, increases the mechanical properties of aluminium [4]. Many researches were done through powder metallurgy by incorporating ceramic particles as reinforcements on pure aluminium whereas, in this work, a novel idea of reinforcing ceramic particles in aluminium 7075 alloy is attempted. Powders of aluminium 7075 were generated through ball milling for this work. This paper focuses on further enhancement of the properties of aluminium 7075 alloy through powder metallurgy process by incorporating $\mathrm{SiC}$ and $\mathrm{TiC}$ as a hybrid reinforcement.

\section{Fabrication by Powder Metallurgy}

RSM is a collection of mathematical and statistical techniques that are useful for the modeling and analysis of problems in which a response of interest is influenced by several variables and the objective is to optimize this response [1]. The Design Expert version 7 software was used to develop the design matrix for conducting the experimentation and same software was used to optimize the process parameters [8]. Table 1 shows the design matrix with coded value and actual values of the process parameters selected in this work. Al 7075 rod of $25 \mathrm{~mm}$ in diameter was turned in lathe machine and scraps are collected with the ball milling; the scraps are made as the powder [9]. By using the Design Expert software, SiC and $\mathrm{TiC}$ were added according to the matrix along with $\mathrm{Al}$ 7075 and the mixture was blended well. The mixed powders of varying proportions were shown in Figure 1.

The blended powder was poured into the die and compacted in certain pressure (20-25 tonnes) using universal testing machine which was shown in Figure 2.

The green compact was sintered in the furnace at $75 \%$ of the melting point of $\mathrm{Al} 7075\left(550^{\circ} \mathrm{C}\right)$ and then the sample was allowed to cool for 8 hours in the furnace. Sintered samples were shown in Figure 3.

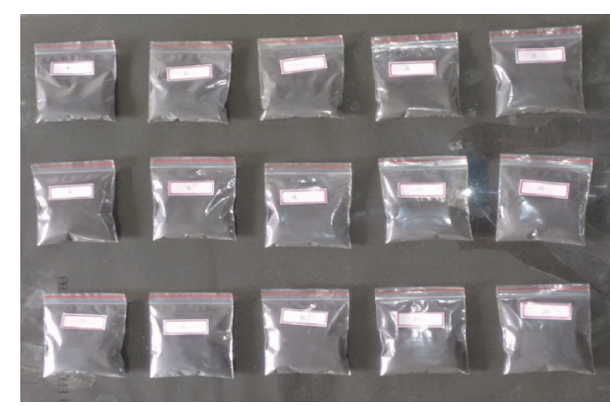

Figure 1: Blended powders based on design matrix.

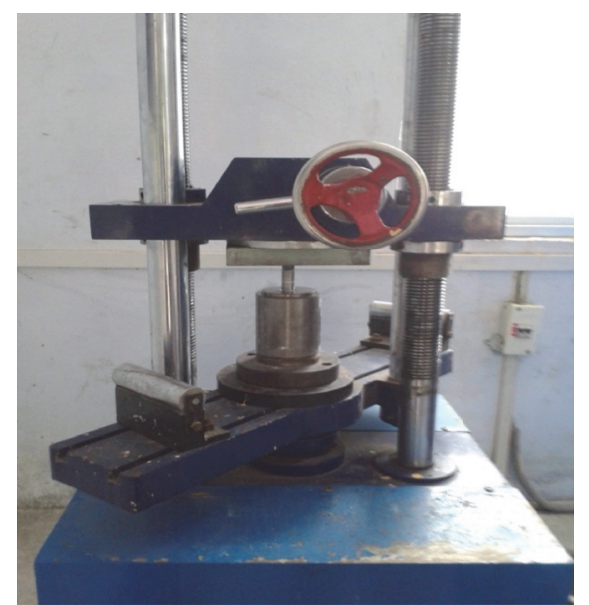

FIGURE 2: Compaction process in UTM machine.

\section{Mechanical Tests}

3.1. Microhardness. The hardness of the sample was measured using a micro-Vickers hardness measuring machine and a 


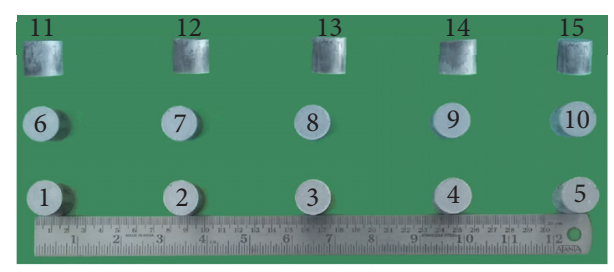

FIGURE 3: Sintered samples based on design matrix. (1) $100 \%$ of $\mathrm{Al}$, $0 \%$ of $\mathrm{SiC}$, and $8 \%$ of $\mathrm{TiC}$. (2) $80 \%$ of $\mathrm{Al}, 8 \%$ of $\mathrm{SiC}$, and $8 \%$ of $\mathrm{TiC}$. (3) $90 \%$ of $\mathrm{Al}, 4 \%$ of $\mathrm{SiC}$, and $0 \%$ of $\mathrm{TiC}$. (4) $100 \%$ of $\mathrm{Al}, 0 \%$ of $\mathrm{SiC}$, and $0 \%$ of TiC. (5) $80 \%$ of $\mathrm{Al}, 0 \%$ of $\mathrm{SiC}$, and $8 \%$ of $\mathrm{TiC}$. (6) $90 \%$ of $\mathrm{Al}, 0 \%$ of $\mathrm{SiC}$, and $4 \%$ of $\mathrm{TiC}$. (7) $90 \%$ of $\mathrm{Al}, 4 \%$ of $\mathrm{SiC}$, and $4 \%$ of TiC. (8) $80 \%$ of $\mathrm{Al}, 8 \%$ of $\mathrm{SiC}$, and $0 \%$ of TiC. (9) $100 \%$ of $\mathrm{Al}, 8 \%$ of $\mathrm{SiC}$, and $8 \%$ of $\mathrm{TiC}$. (10) $90 \%$ of $\mathrm{Al}, 8 \%$ of $\mathrm{SiC}$, and $4 \%$ of TiC. (11) $90 \%$ of $\mathrm{Al}, 4 \%$ of $\mathrm{SiC}$, and $8 \%$ of $\mathrm{TiC}$. (12) $100 \% \mathrm{Al}, 8 \%$ of $\mathrm{SiC}$, and $0 \%$ of TiC. (13) $80 \%$ of $\mathrm{Al}, 4 \%$ of $\mathrm{SiC}$, and $4 \%$ of TiC. (14) $100 \%$ of $\mathrm{Al}$, $0 \%$ of $\mathrm{SiC}$, and $0 \%$ of TiC. (15) $100 \% \mathrm{Al}, 4 \%$ of $\mathrm{SiC}$, and $4 \%$ of $\mathrm{TiC}$.

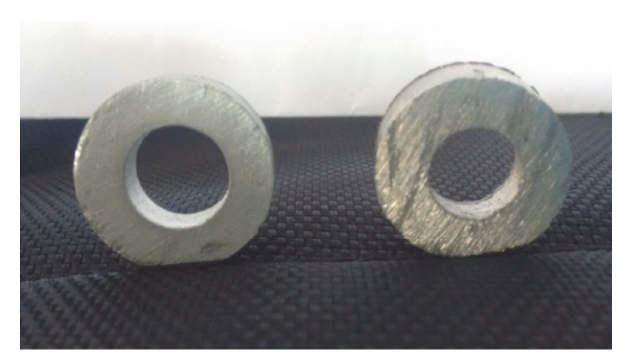

FIGURE 4: Specimens prepared for ring compression test.

load of $1.962 \mathrm{~N}$ was applied for 10 seconds. To avoid error possibility, a minimum of five hardness readings were taken for each sample and they were averaged. Theoretically, the hardness should be uniform throughout sample prepared, if the particles distribution was uniform throughout compaction. The experimentation result shows that the Vickers hardness of the compaction was varying from $33.2 \mathrm{HV}$ to 55.2 HV. The highest hardness value (52.12) obtained for sample 11 was produced with the combination of $90 \%$ of $\mathrm{Al}$, $4 \%$ of $\mathrm{SiC}$, and $8 \%$ of $\mathrm{TiC}$.

3.2. Ring Compression Test. The specimens were machined as per the standard ratio of $6: 3: 2$ for the ring compression test to facilitate the measurement of coefficient of friction. As per the standard proportions ratio $(6: 3: 2)$, the outer diameter of the specimens has been taken as $20 \mathrm{~mm}$ and inner diameter as $10 \mathrm{~mm}$ with the initial height of $6.6 \mathrm{~mm}$. The specimens prepared were shown in Figure 4.

Universal testing machine was utilized for conducting ring compression test and case hardened steel plate was utilized to apply a maximum load of $200 \mathrm{KN}$ and the rings were compressed. The lubricant, zinc stearate was applied to the top, bottom, and lateral surfaces of the ring specimen before testing. The dimensions of outer and inner diameters of each samples were measured using Vernier caliper after the test. However, because of barreling and irregularity on both outer and inner cylindrical surfaces of the specimen, several diametric readings were taken and a median value

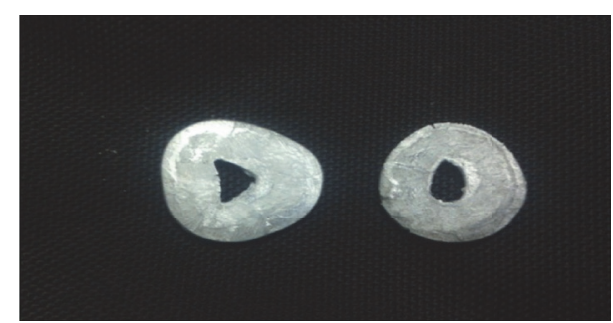

FIGURE 5: Deformation of specimen after ring compression testing.

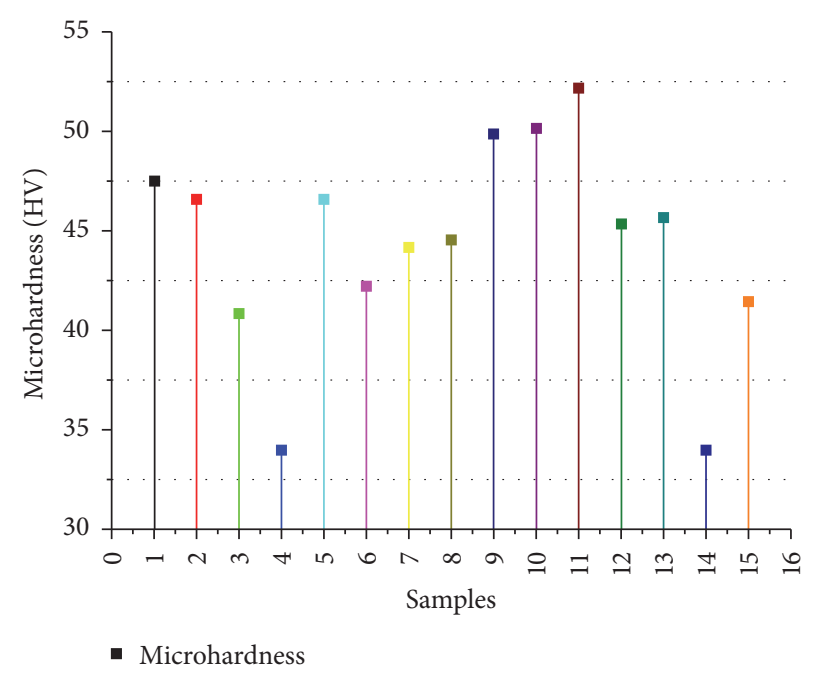

FIGURE 6: Microhardness of the samples.

was recorded. Figure 5 shows deformation of specimen after carrying ring compression test.

\section{Results and Discussion}

4.1. Microhardness Results. The results of microhardness test of the samples produced through powder metallurgy of $\mathrm{Al}$ 7075 alloy reinforced with nano-SiC and nano $\mathrm{TiC}$ were shown in Figure 6. The microhardness results of the samples are attributed to the fact that pure aluminium 7075 shows lowest microhardness when compared to other samples reinforced with $\mathrm{SiC}$ and $\mathrm{TiC}$. Incorporation of $\mathrm{TiC}$ alone in the aluminium matrix leads to the higher microhardness value which is evident in sample 1 which has $100 \%$ of $\mathrm{Al}, 0 \%$ of $\mathrm{SiC}$, and $8 \%$ of $\mathrm{TiC}$. However, addition of $\mathrm{SiC}$ increases the microhardness value which can be noted in sample 8 which was produced with $100 \%$ of $\mathrm{Al}, 8 \%$ of $\mathrm{SiC}$, and $8 \%$ of TiC.

Figure 7 shows indentation of the microhardness test of pure aluminium. Figure 8 shows the indentation of sample 10 which was produced with $100 \%$ of $\mathrm{Al}, 8 \%$ of $\mathrm{SiC}$, and $8 \%$ of TiC. It is evident from these figures that the hardness of the composite material was much higher than that of the pure metal. It was observed that the hardness of the composite material increases with the increase in weight\% of $\mathrm{TiC}$ and $\mathrm{SiC}$ content. The addition of $\mathrm{TiC}$ and $\mathrm{SiC}$ makes the ductile Al 7075 alloy into more brittle in nature. Similarly, the incorporation of $\mathrm{TiC}$ and $\mathrm{SiC}$ in the aluminium matrix enhances the hardness of the samples. Hardness test image of 


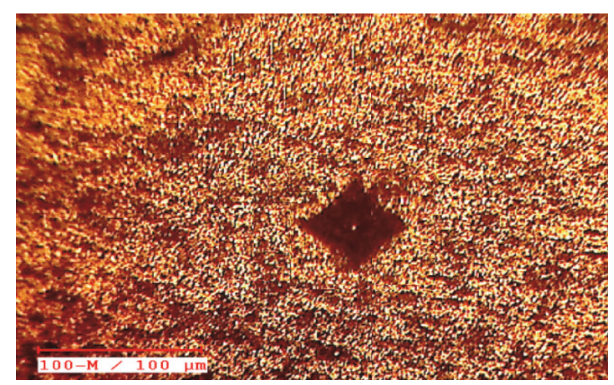

FIGURE 7: Indentation image of the sample produced with $100 \%$ of $\mathrm{Al}, 0 \%$ of $\mathrm{SiC}$, and $0 \%$ of $\mathrm{TiC}$ (pure aluminium).

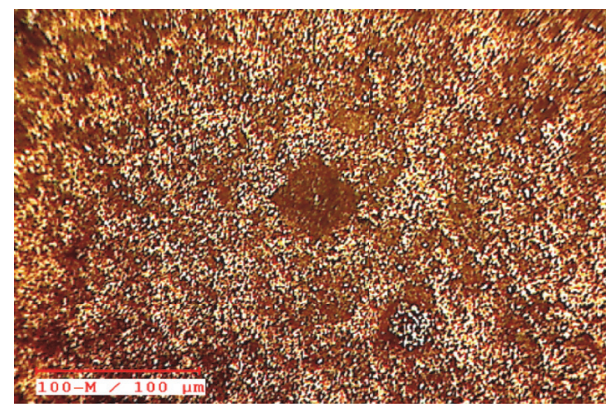

FIGURE 8: Indentation image of the sample produced with $100 \%$ of $\mathrm{Al}, 8 \%$ of $\mathrm{SiC}$, and $8 \%$ of $\mathrm{TiC}$.

specimen 10 with composition of $100 \%$ of $\mathrm{Al}, 8 \%$ of $\mathrm{SiC}$, and $8 \%$ of $\mathrm{TiC}$ was shown in Figure 8.

4.2. Ring Compression Test. Ring compression test is the most applied method for finding contact conditions in the bulk deformation process. Hence in this work, coefficient of friction was calculated by adopting ring compression test [10]. Coefficient of friction is determined by A.G. Male and M.G. Cockroft calibration chart by measuring the percentage change in the internal diameter of the specimen after compaction [11]. When the hollow short cylinder is compressed by universal testing machine with a flat, parallel, and rigid plates, the diameter of the hole may either increase or decrease depending upon the amount of friction offered by the material [12]. Imposing the coefficient of friction values of all the samples on the calibration chart clearly depicts that pure aluminium sample has highest coefficient of friction value when compared to other samples. It is attributed to the higher ductility of pure aluminium and subsequently its sticking friction nature. This higher coefficient of friction would have detrimental effect especially when MMC produced by powder metallurgy route are subjected to forging [13]. Coefficient of friction calibration curve is shown in Figure 9.

4.3. Surface Contours of RSM. The plot shown in Figure 10 is attributed to the fact that when wt $\%$ of $\mathrm{SiC}$ is increased, it leads to increase in the hardness value of the compacted specimen. It also reveals that $\mathrm{SiC}$ incorporation leads to better hardness in such a way that amount of $\mathrm{SiC}$ added during the

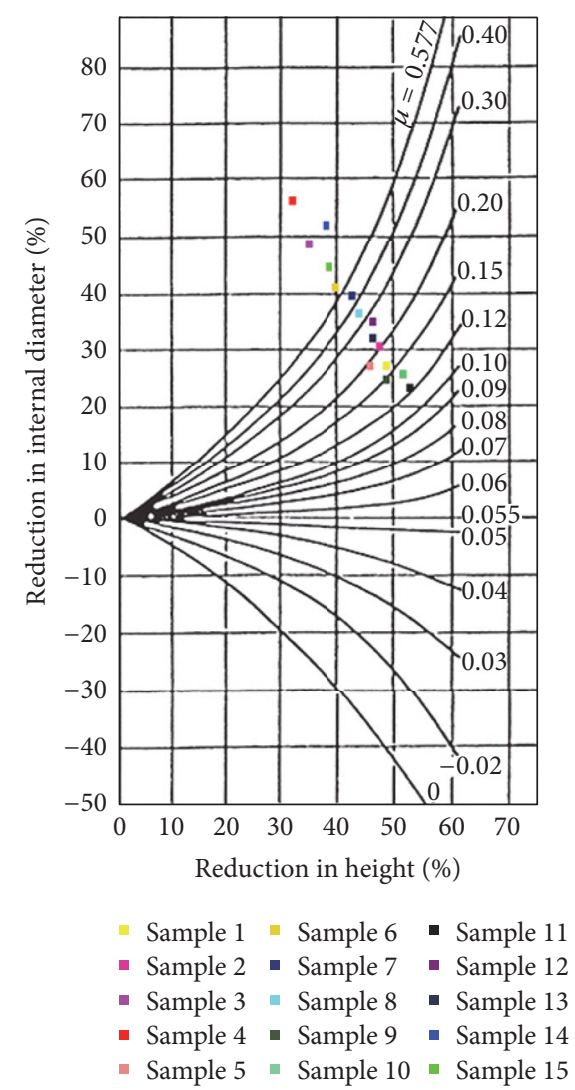

Figure 9: Coefficient of friction calibration curve.

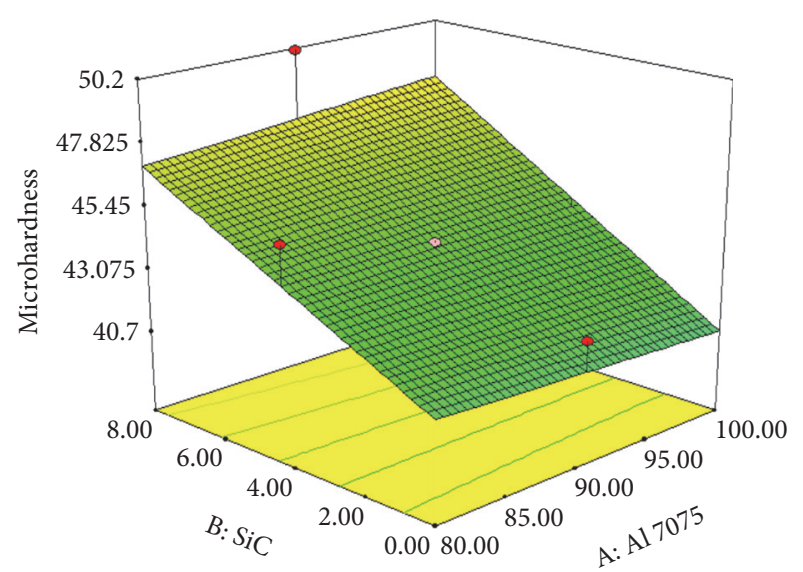

FIGURE 10: Surface contour representation of $\mathrm{Al} 7075$ and SiC versus microhardness.

process is directly proportional to increase hardness value. Figure 11 shows surface contour representation of amount of $\mathrm{Al} 7075$ and amount of $\mathrm{TiC}$ versus hardness value.

Figure 12 shows surface contour representation of amount of aluminium and the amount of $\mathrm{TiC}$ versus hardness value. It indicates that with the increase in amount of TiC the MMC increases the hardness value of the specimen gradually. Hence incorporation of $\mathrm{TiC}$ in the aluminium matrix is directly proportional to hardness value [8]. 


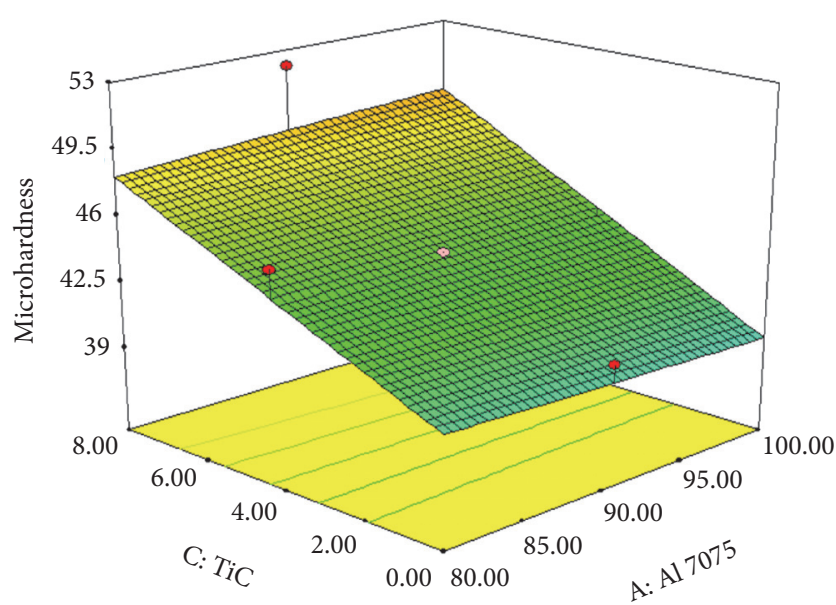

FIGURE 11: Surface contour representation of $\mathrm{Al} 7075$ and TiC versus microhardness.

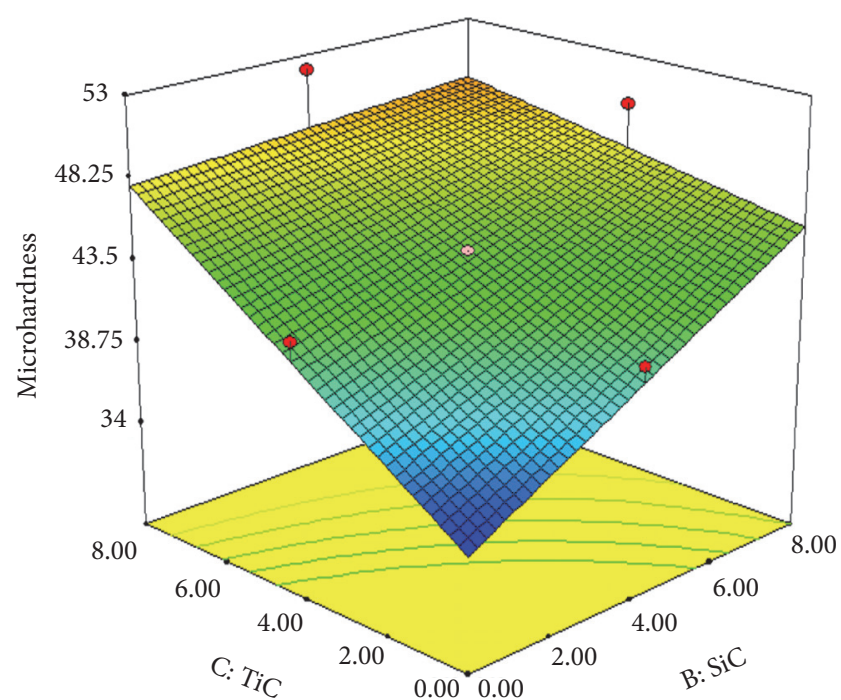

Figure 12: Surface contour representation of $\mathrm{SiC}$ and $\mathrm{TiC}$ versus microhardness.

These plots reveals that increase in the \% of $\mathrm{SiC}$ and $\mathrm{TiC}$ leads to further increases in the hardness value which brings to a conclusion that increase in the percentage of $\mathrm{SiC}$ and $\mathrm{TiC}$ is directly proportional to hardness value [9].

\section{Conclusions}

Based on the study conducted on the $\mathrm{TiC}$ and $\mathrm{SiC}$ containing $\mathrm{Al} 7075$ composite material, the following conclusions have been arrived.

By measuring the microhardness with various samples a reasonable comparison could be made and out of them the results were improved for various compositions. The higher value of microhardness was $52.12 \mathrm{HV}$ which can be obtained with $90 \%$ of $\mathrm{Al} 7075,4 \%$ of $\mathrm{SiC}$, and $8 \%$ of $\mathrm{TiC}$. The ring compression test reveals that the sample with $90 \%$ of $\mathrm{Al} 7075$, $4 \%$ of $\mathrm{SiC}$, and $4 \% \mathrm{TiC}$ of density has lowest coefficient of friction than that of the other samples. This is due to the addition of $\mathrm{SiC}$ and $\mathrm{TiC}$ which leads to the increase in wear resistance of the MMC. In sample, 100\% of $\mathrm{Al} \mathrm{7075,0 \%}$ of $\mathrm{SiC}$, and $0 \%$ of $\mathrm{TiC}$, the maximum value of coefficient of friction was attained and similarly, it experiences lowest microhardness. This phenomena clearly depicts the fact that incorporation of $\mathrm{SiC}$ and $\mathrm{TiC}$ along the aluminium matrix increases the wear resistant property of the alloy.

\section{Competing Interests}

The authors declare that they have no competing interests.

\section{References}

[1] M. Reihanian, S. R. Asadullahpour, S. Hajarpour, and K. Gheisari, "Application of neural network and genetic algorithm to powder metallurgy of pure iron," Materials and Design, vol. 32, no. 6, pp. 3183-3188, 2011.

[2] N. Nandakumar and R. Vivekanandan, "Experimental investigation of corrosion characteristics on Al6063 hybrid metal matrix composites," in Proceedings of the International Conference on Advances in Materials, Manufacturing and Applications, p. 27, Bengaluru, India, April 2015.

[3] R. Chandramouli, T. K. Kandavel, D. Shanmugasundaram, and T. A. Kumar, "Deformation, densification, and corrosion studies of sintered powder metallurgy plain carbon steel preforms," Materials and Design, vol. 28, no. 7, pp. 2260-2264, 2007.

[4] S. C. Tjong and Z. Y. Ma, "High-temperature creep behaviour of powder-metallurgy aluminium composites reinforced with $\mathrm{SiC}$ particles of various sizes," Composites Science and Technology, vol. 59, no. 7, pp. 1117-1125, 1999.

[5] M. Wahba, Y. Kawahito, K. Kondoh, and S. Katayama, "A fundamental study of laser welding of hot extruded powder metallurgy (P/M) AZ31B magnesium alloy," Materials Science and Engineering: A, vol. 529, no. 1, pp. 143-150, 2011.

[6] Y. C. Lin, H. C. Li, S. S. Liou, and M. T. Shie, "Mechanism of plastic deformation of powder metallury metal matrix composites of $\mathrm{Cu}-\mathrm{Sn} / \mathrm{Sic}$ and 6061/SiC under compressive stress," Materials Science and Engineering A, vol. 373, no. 1-2, pp. 363-369, 2004.

[7] L. Shi, C. Sun, P. Gao, F. Zhou, and W. Liu, "Mechanical properties and wear and corrosion resistance of electrodeposited Ni$\mathrm{Co} / \mathrm{SiC}$ nanocomposite coating," Applied Surface Science, vol. 252, no. 10, pp. 3591-3599, 2006.

[8] S. Gopalakannan, T. Senthilvelan, and S. Ranganathan, "Modeling and optimization of EDM process parameters on machining of $\mathrm{Al} 7075-\mathrm{B}_{4} \mathrm{C}$ MMC using RSM," Procedia Engineering, vol. 38, pp. 685-690, 2012.

[9] S. Tahamtan, A. Halvaee, M. Emamy, and M. S. Zabihi, "Fabrication of $\mathrm{Al} / \mathrm{A} 206-\mathrm{Al}_{2} \mathrm{O}_{3}$ nano/micro composite by combining ball milling and stir casting technology," Materials and Design, vol. 49, pp. 347-359, 2013.

[10] T. Senthilvelan, K. Raghukandan, and A. Venkatraman, "Modelling of process parameters on the working of $\mathrm{P} / \mathrm{M}$ copper preforms," Journal of Materials Processing Technology, vol. 142, no. 3, pp. 767-772, 2003.

[11] R. Narayanasamy and K. S. Pandey, "A study on the barrelling of sintered iron preforms during hot upset forging," Journal of Materials Processing Technology, vol. 100, no. 1-3, pp. 87-94, 2000.

[12] E. Rajesh and M. SivaPrakash, "Analysis of friction factor by employing the ring compression test under different lubricants," 
International Journal of Scientific \& Engineering Research, vol. 4, no. 5, 2013.

[13] K. P. Rao and K. Sivaram, "A review of ring-compression testing and applicability of the calibration curves," Journal of Materials Processing Technology, vol. 37, no. 1-4, pp. 295-318, 1993. 

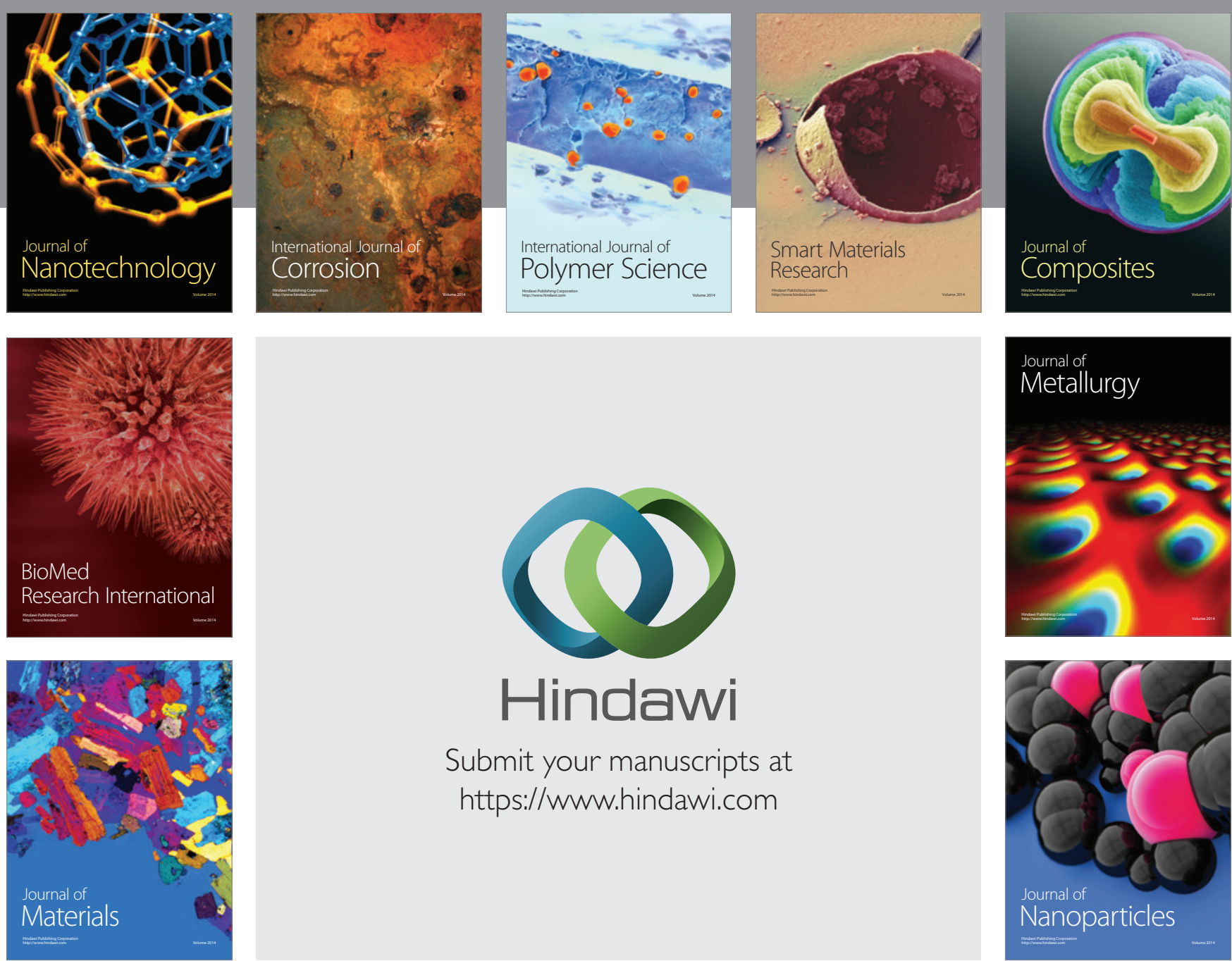

\section{Hindawi}

Submit your manuscripts at

https://www.hindawi.com

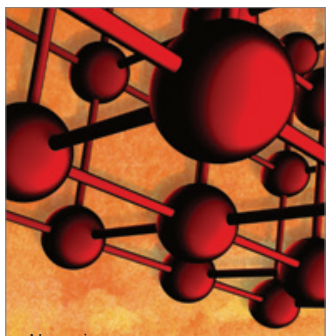

Materials Science and Engineering
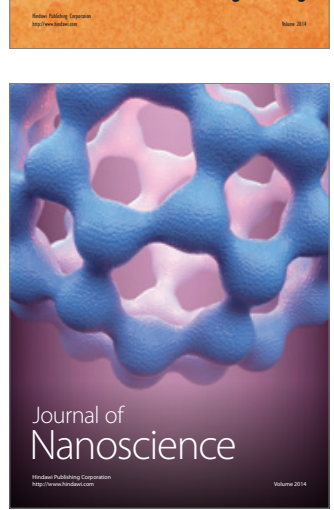
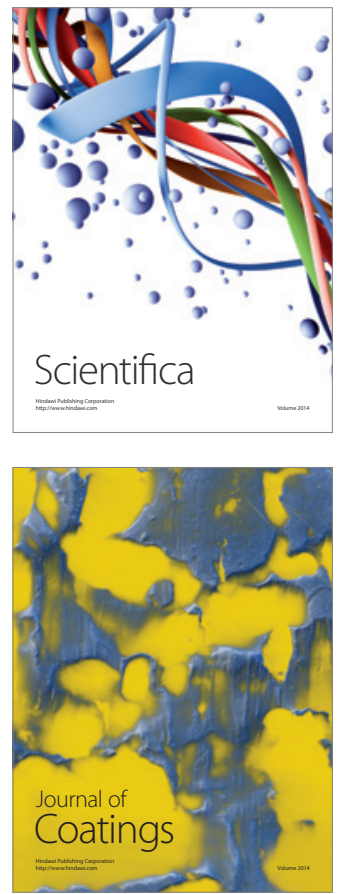
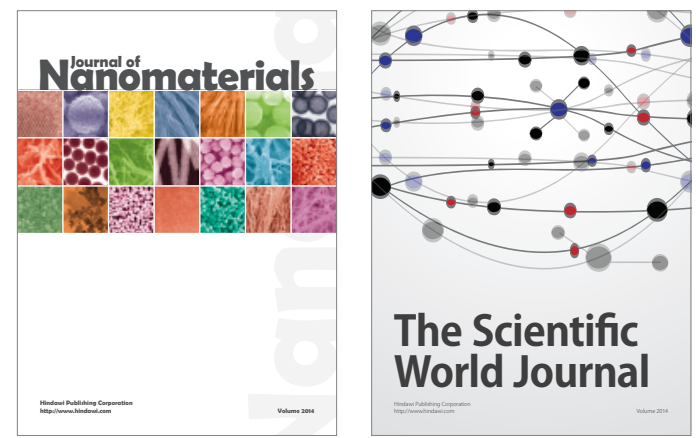

The Scientific World Journal
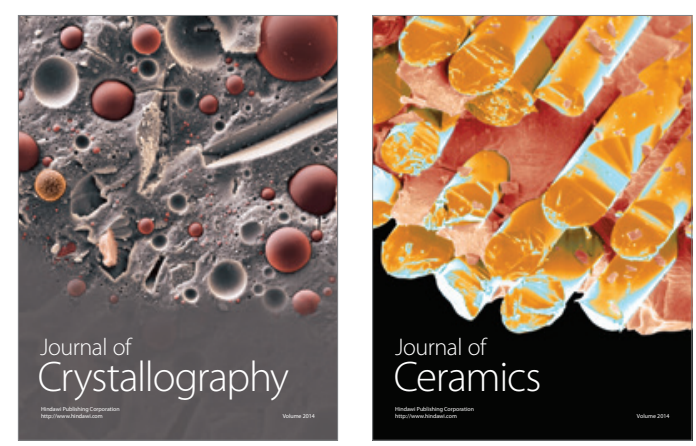
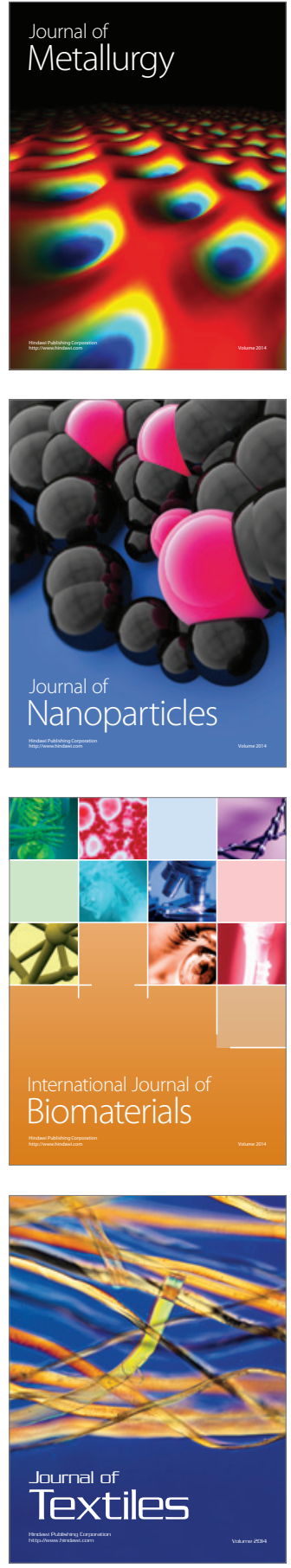